Document downloaded from:

http://hdl.handle.net/10251/117053

This paper must be cited as:

Santos-Juanes Jordá, L.; Amat Payá, AM.; Arqués Sanz, A. (2017). Strategies to Drive Photo-Fenton Process at Mild Conditions for the Removal of Xenobiotics from Aqueous Systems. Current Organic Chemistry. 21(12):1074-1083.

https://doi.org/10.2174/1385272821666170102150337

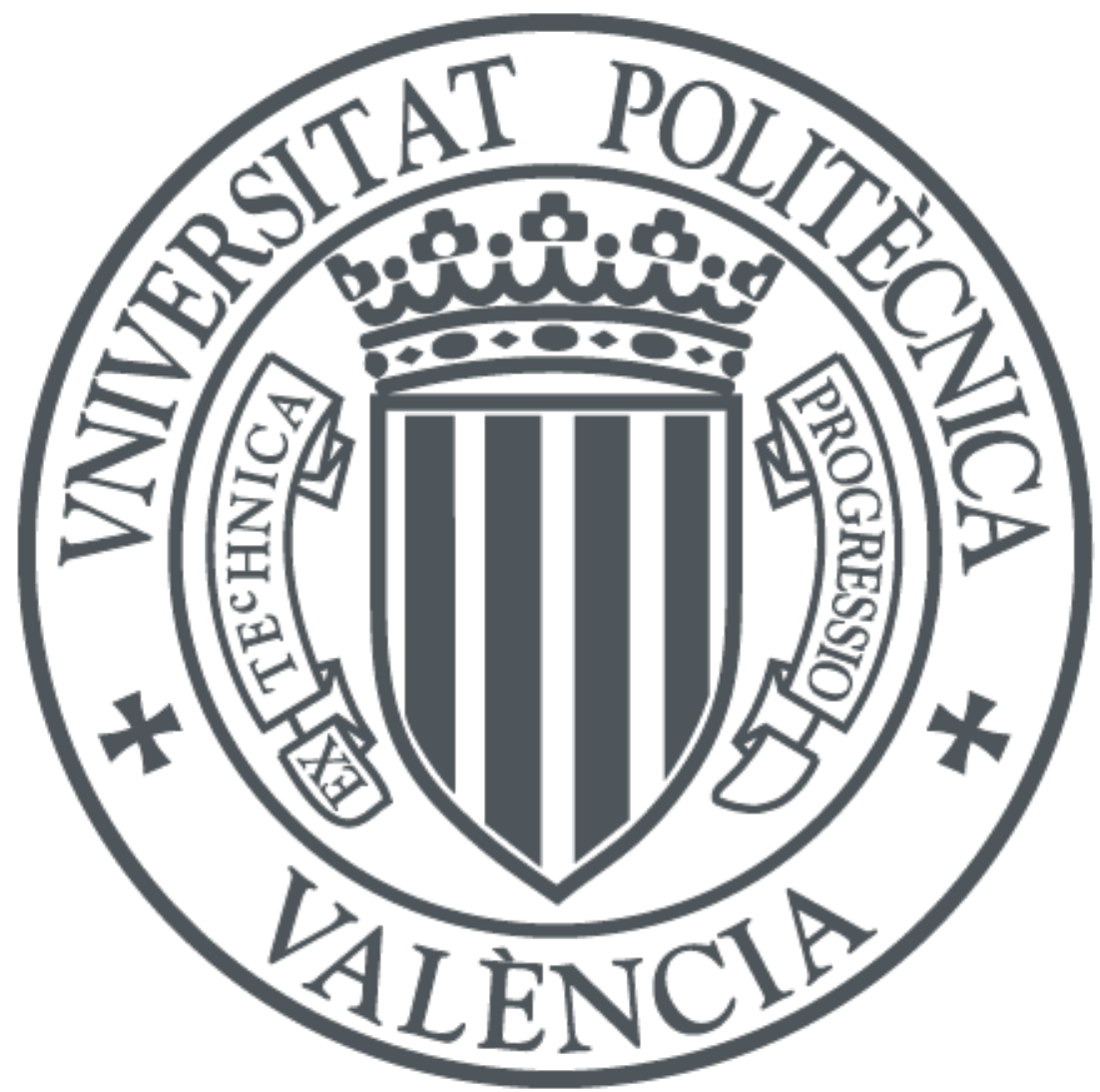

The final publication is available at

https:dx.doi.org/10.2174/1385272821666170102150337

Copyright Bentham Science

Additional Information 


\title{
Strategies to Drive Photo-Fenton Process at Mild Conditions for the Removal of Xenobiotics from Aqueous Systems
}

\author{
Lucas Santos-Juanes $^{\mathrm{a}}$, Ana M. Amat ${ }^{\mathrm{b}}$ and Antonio Arques ${ }^{* \mathrm{~b}}$
}

${ }^{a}$ Grupo de Procesos de Oxidación Avanzada Departmento de Máquinas y Motores Térmicos, Campus d'Alcoi of Universitat Politècnica de València, Alcoy, Spain; ${ }^{b}$ Grupo de Procesos de Oxidación Avanzada Departmento de Ingeniería Textil y Papelera, Campus d'Alcoi of Universitat Politècnica de València, Alcoy, Spain

Abstract: The aim of this paper is to provide an overview on the different approaches that can be employed to drive a photo-Fenton process under mild conditions, using both heterogeneous and homogeneous iron sources. For this purpose, sections are devoted to the following strategies: a) addition of iron at low concentrations; b) using the matrix of the effluent in order to avoid deactivation of iron; c) addition of chemical auxiliaries to form photoactive complexes with iron, such as carboxylates, chelating agents and humic-like macromolecules; d) strategies leading to the application of heterogeneous photo-Fenton process, by using iron-based solid particles or by hosting iron on different supports and; e) using heterogeneous iron sources as a reservoir for constant dosing of homogeneous iron photocatalyst. In particular, the review will focus on the elimination of emerging pollutants (e.g. drugs, personal care products or pesticides at low concentrations) which are the effluents where applying neutral photo-Fenton seems especially meaningful, although relevant works with other families of pollutants are also considered.

Keywords: wastewater treatment, photo-Fenton, mild pH, complexing agents, heterogeneous process, xenobiotics.

\section{INTRODUCTION}

Photo-Fenton can be found among the most promising photochemical advanced oxidation processes that has been employed for the removal of organic pollutants. It is based on the Fenton reagent, which consists in a mixture of iron salts and hydrogen peroxide, in which iron behaves as a catalyst to decompose hydrogen peroxide into highly oxidizing species, such as hydroxyl radical $(\mathrm{OH})$. The reaction is greatly enhanced by UV-visible irradiation $(\lambda<500 \mathrm{~nm})$. Although the mechanism is still under discussion, there is an agreement that the key reactions are described by equations 1-2 [1]. However, the involvement of other reactive species, such as highly oxidized iron species (e.g. ferryl cation) cannot be ruled out and may play an important role at some experimental conditions.

$$
\begin{aligned}
& \mathrm{Fe}^{2+}+\mathrm{H}_{2} \mathrm{O}_{2} \rightarrow \mathrm{Fe}^{3+}+\cdot \mathrm{OH}+\mathrm{OH}^{-} \\
& \mathrm{Fe}(\mathrm{OH})^{2+}+\mathrm{h} v \rightarrow \mathrm{Fe}^{2+}+\cdot \mathrm{OH}
\end{aligned}
$$

The effect of light can be understood, as equation (2) requires irradiation. For this reason $\mathrm{Fe}(\mathrm{OH})^{2+}$, the species that suffers photolysis is key in photo-Fenton. It is well established that $\mathrm{Fe}(\mathrm{OH})^{2+}$ reaches its highest concentration at a $\mathrm{pH}$ of ca. 2.8 , which has been reported as the optimum $\mathrm{pH}$ for photoFenton [2]. This highly acidic $\mathrm{pH}$ represents a major drawback for the economic viability of this process, as costs related with $\mathrm{pH}$ modification (in most cases acidification followed by neutralization before discharge) are significant [3].

*Address correspondence to this author at Campus d'Alcoi of Universitat Politècnica de València, Alcoy, Spain; Tel/Fax: ++34-966528418, ++34966528438; E-mails: aarques@txp.upv.es
This is especially true when applying photo-Fenton to deal with effluents containing pollutants of high concern but present at low concentrations, such as the emerging pollutants. In fact, there is recent literature on the use of photo-Fenton for this purpose (e.g. pharmaceuticals, personal care products or effluents of wastewater treatments plants). Due to the low concentration of these xenobiotics (typically $\mu \mathrm{g} / \mathrm{L}$ or even $\mathrm{ng} / \mathrm{L}$ ), the reaction time is expected to be short and a certain loss of efficiency of the process could be acceptable if $\mathrm{pH}$ modification can be avoided or minimized.

Different strategies have been tested in recent years to apply photo-Fenton at mild conditions. In general, they can be classified in two wide groups, namely those trying to keep photochemically active iron species in solution at mild $\mathrm{pH}$ and those adding heterogeneous iron sources (although solubilized iron is partly or completely responsible for the reaction). Within the first group can be found: a) using iron at low concentrations, b) taking advantage of the matrix of the effluent and c) addition of complexing agents. The approaches involving heterogeneous iron sources can be divided in d) those strategies trying to apply, at least partly, an heterogeneous photo-Fenton process and e) using the heterogeneous iron as a reservoir for constant dosing of homogeneous iron photocatalyst.

With this background, the aim of this review is to report on recent research devoted to the application of neutral or mild acidic photo-Fenton to treat xenobiotics following any of the five approaches above mentioned; rather than an exhaustive 
literature survey, significant examples on each approach are provided and discussed.

Finally, other processes related to photo-Fenton have also been studied at circumneutral $\mathrm{pH}$. One possibility is to substitute iron by other cation, such as copper, aluminum, chromium or cobalt to drive a photo-Fenton like process, as recently reviewed by Bokare and Choi [4]; also photo-electroFenton has been used for this purpose, as recently reviewed [5]. However, we think that they fall out of the scope of this work, as also happens with the use of mild photo-Fenton for disinfection [6,7].

\section{PHOTO-FENTON WITH IRON AT LOW CONCENTRATIONS}

As indicated in the previous section, formation of iron oxides or hydroxides, unable to drive a photo-Fenton process, represents the major hindrance to extend this treatment to milder $\mathrm{pH}$ values. According to Figure 1, the solubility of $\mathrm{Fe}(\mathrm{III})$ decreases with $\mathrm{pH}$, as the predominant species varies from highly soluble $\mathrm{Fe}^{3+}$ to the very insoluble $\mathrm{Fe}(\mathrm{OH})_{3}$. However, even at neutral $\mathrm{pH}$ a small fraction of iron remains soluble, partly as $\mathrm{Fe}(\mathrm{OH})^{2+}$.

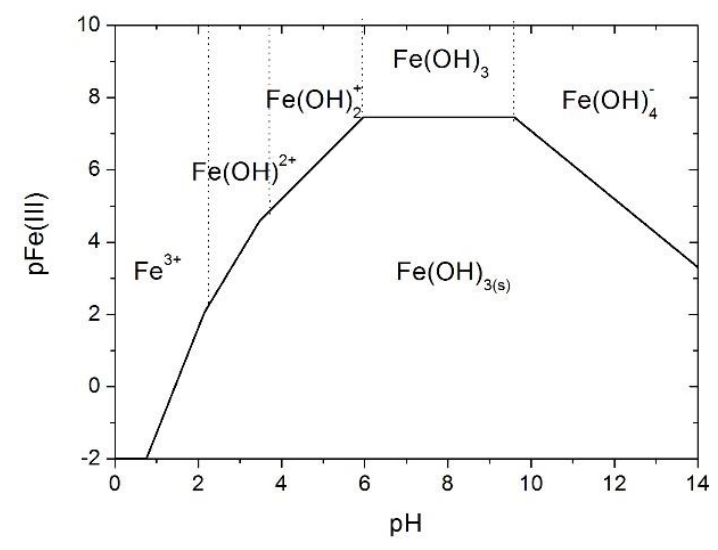

Figure 1: Iron speciation vs. $\mathrm{pH}$ and iron concentration.

One strategy that has been tested is to add iron at low concentrations (ca. $1 \mathrm{mg} / \mathrm{L}$ or even less) in order to be close to the amount of iron that is active at the working $\mathrm{pH}$, thus minimizing the loss of iron by precipitation. This procedure might be meaningful to treat pollutants at trace concentrations, as even a low amount of catalyst might be able to generate a sufficient quantity of reactive species to remove the pollutants within an acceptable irradiation time. Some recent examples can be found in literature [8-17].

For instance, this approach has been employed to remove eight micropollutants in the presence of low concentrations of iron $(\mu \mathrm{M})$. Irradiations were performed with UVC; however important degradations were also found in the absence of $\mathrm{Fe}$, that could be associated to photolysis [9]. Furthermore, modification of $\mathrm{pH}$ throughout the process and generation of carboxylic by-products may enhance the process. The role of carboxylic acids will be discussed in section 4; regarding to the $\mathrm{pH}$ modification, it is common that photo-Fenton results in an acidification of the solution and iron that was inactive at the initial $\mathrm{pH}$ could be increasingly activated when approaching to $\mathrm{pH}=3$. In fact, a limit for this homogeneous photo-Fenton has been established at $\mathrm{pH}=5.7$ for resorcinol degradation under solar irradiation [18]; that means that once solution reaches this value, the process is greatly accelerated.

Photo-Fenton has also been driven under solar irradiation with real effluents; Klamerth et al showed that pollutants at trace amounts can be removed without $\mathrm{pH}$ modification using low concentrations of iron and hydrogen peroxide. However, it was necessary to decrease slightly the $\mathrm{pH}$ in order to remove bicarbonates from the solution. Interestingly, this study has been performed with a real effluent from a wastewater treatment plant, which has been spiked with different pollutants [17]. In this context, it is important to remark that when low amounts of iron are present, the matrix of the sample plays a very important role, and very different results have been obtained when working with tap or distilled water. In fact, some ions such as bicarbonate have been reported to be detrimental for the process, either by inducing changes in the coordination sphere of iron or by scavenging the formed reactive species. On the other hand, presence of organic matter may enhance the process, most probably because of its ability to complex iron.

Alternatively, some authors have tried to drive photoFenton at mild $\mathrm{pH}$ conditions by continuously adding iron in order to compensate for the loss due to precipitation. This procedure has been followed to remove a mixture of pesticides under solar irradiation, and rate constants close to those measured at acidic medium were reached. However, this methodology is limited by the higher amount of iron that is required and the difficult determination of the optimal sequence for iron addition [19].

\section{USING THE MATRIX OF THE EFFLUENT}

Some recent papers have shown that photo-Fenton can be applied at $\mathrm{pH}$ above 3 without important loss of efficiency or even shifting the optimum $\mathrm{pH}$ towards higher values. This is a very important issue that should be studied when dealing with a new type of effluent as, if acidification until $\mathrm{pH}$ close to 3 could be avoided, important economic and ecological advantages related with $\mathrm{pH}$ modification would be achieved. In particular, in samples containing phenols, the optimum $\mathrm{pH}$ was shifted to values close to four, most probably due to complexation of iron with the phenolic compounds [20]. This might be an important point when dealing with phenols-rich effluents such as food processing wastewaters.

Another interesting example is the removal of natural organic matter in a tertiary treatment for drinking water. These substances generate disinfection by products, and hence, they have to be removed before chlorination. When applying solar photo-Fenton as a tertiary treatment with low concentrations 
of iron, very similar efficiencies were found in the range of $\mathrm{pH}$ between 3 and 7. In particular, good results were reached with $1 \mathrm{mg} / \mathrm{L}$ of iron at $\mathrm{pH}=5$ [21]. Another work also demonstrated that, under simulated sunlight, removal of humic acids by photo-Fenton was very efficient until $\mathrm{pH}$ close to 4 , and noticeable reaction was observed throughout the studied $\mathrm{pH}$ range [22]. These results might be attributed to the ability of humic substances to complex iron, as will be reported in next section. This effect might involve that effluents containing humic-like substances (e.g. landfill leachates) could be treated at higher $\mathrm{pH}$ values.

Another group of effluents that can be used is metal industry wastes. In some cases, other metals rather than iron have been employed, (e.g. copper). For instance, SantosJuanes et al. [23] used metal finishing effluents containing high amounts of copper to remove the cyanide that was present; for this purpose hydrogen peroxide was added and solar photo-Fenton was driven at $\mathrm{pH}=12$. Also metallurgical slags have been employed as photo-Fenton-like photocatalyst; however these processes should be predominantly considered as "in situ" iron generation and will be studied in section 6 .

Finally, in a very recent work, iron present in natural waters $(0.3 \mathrm{mg} / \mathrm{L})$ was employed to drive a photo-Fenton process at $\mathrm{pH}=7$ to remove the pesticide 2,4-dichlorophenoxyacetic acid under simulated sunlight. This experiment shows that iron present in natural effluents can be used to treat pollutants present in groundwater [24].

\section{ADDITION OF COMPLEXING AGENTS}

In section 3, the possibility of extending the $\mathrm{pH}$ range for photo-Fenton in some effluents has been attributed to the formation of complexes with species present in the matrix. Hence, addition of substances able to form photo-active complexes with iron is a logical step forward and this approach is receiving increasing attention. In general, molecules and macromolecules with carboxy and/or amino groups are good complexing agents for iron, thus preventing formation of iron hydroxides at neutral $\mathrm{pH}$ values. In some cases, they have been demonstrated to drive photo-Fentonlike process. Table 1 summarizes complexing agents that have been employed and their chemical structure, and Table 2 details some examples and conditions in which have been applied.

\section{COMPOUND CHEMICAL STRUCTURE}

OXALATE CITRATE

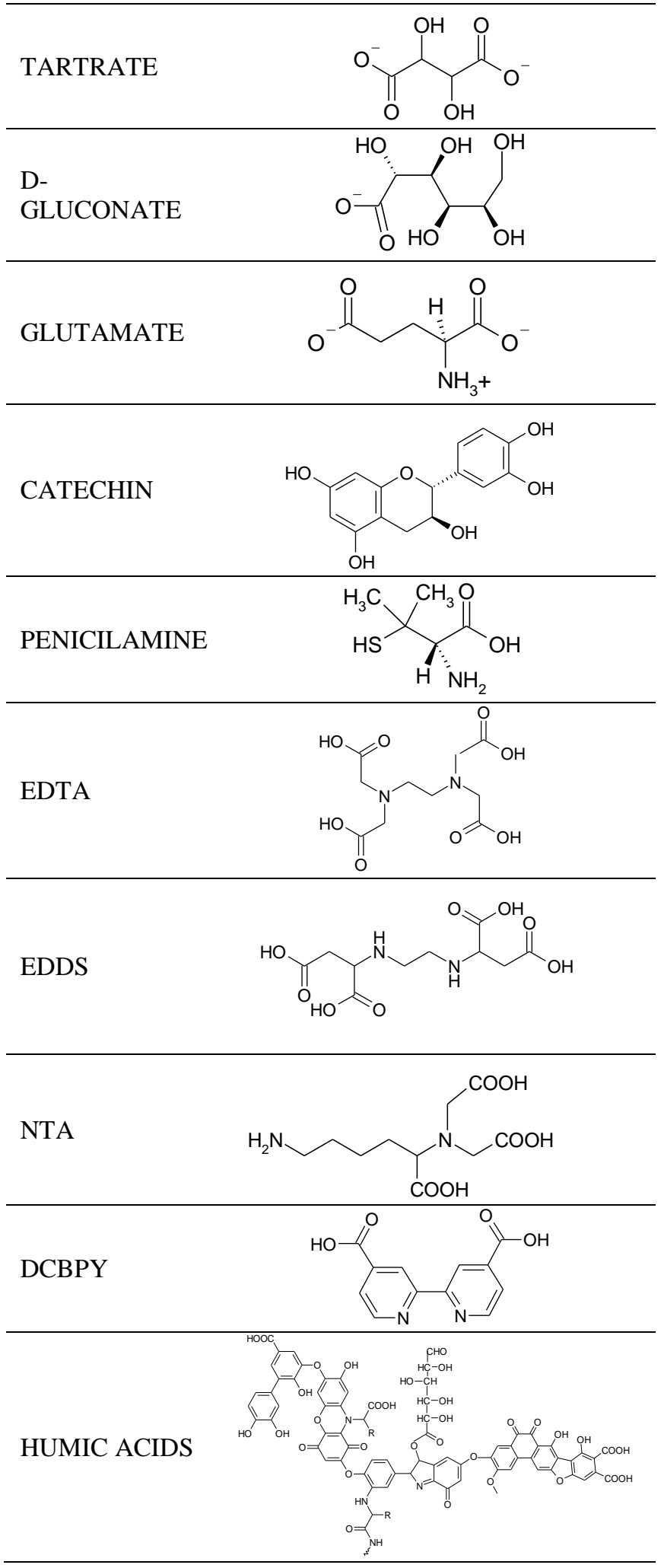

Table 1: Chemical structures of iron complexing agents that have been employed in photo-Fenton process.

\begin{tabular}{cccc}
$\begin{array}{c}\text { Complexing } \\
\text { agent }\end{array}$ & $\mathrm{pH}$ & Pollutant & Cites \\
\hline
\end{tabular}




\begin{tabular}{|c|c|c|c|}
\hline \multirow{8}{*}{ Oxalate } & 5.0 & 2,4-Dichlorophenol & {$[25,26]$} \\
\hline & $3.5-6.5$ & $\begin{array}{c}\text { 3-amino-3- } \\
\text { methylisoxazole }\end{array}$ & {$[27]$} \\
\hline & $2.8-5$ & textile wastewater & [28] \\
\hline & $5-6$ & diclofenac & [29] \\
\hline & $3-7$ & oxytetracycline & {$[30]$} \\
\hline & 7 & sulfamethoxazole & {$[31]$} \\
\hline & 5 & $\begin{array}{c}\text { trimethoprim, } \\
\text { sulfamethoxazole }\end{array}$ & [32] \\
\hline & $6-7$ & rhodamine B & [33] \\
\hline \multirow{7}{*}{ Citrate } & $2.8-5$ & textile wastewater & {$[28]$} \\
\hline & $6-7$ & $\begin{array}{l}\text { carbamazepine, } \\
\text { fluomequine, } \\
\text { ibuprofen, } \\
\text { ofloxacin, } \\
\text { sulfamethoxazole } \\
\end{array}$ & [34] \\
\hline & $3-7$ & oxytetracycline & [30] \\
\hline & 7 & sulfamethoxazole & [31] \\
\hline & 5 & alachlor & [35] \\
\hline & $2.5-7.5$ & terbuthiuron & {$[36]$} \\
\hline & $3.5-8.6$ & atrazine & {$[37]$} \\
\hline \multirow{2}{*}{ Tartrate } & 7 & acetominophen & {$[38]$} \\
\hline & 7 & sulfamethoxazole & {$[31]$} \\
\hline D-Gluconate & $3-7$ & inderal & [39] \\
\hline Catechin & $6-7$ & rhodamine B & [33] \\
\hline Penicillamine & 7 & crotamiton & {$[40]$} \\
\hline \multirow{3}{*}{ EDTA } & 7 & sulfamethoxazole & {$[31]$} \\
\hline & 7 & crotamiton & {$[40]$} \\
\hline & 7 & Methylene blue & {$[41]$} \\
\hline \multirow{10}{*}{ EDDS } & $3,5-6,5$ & $\begin{array}{c}\text { 3-amino-3- } \\
\text { methylisoxazole }\end{array}$ & [27] \\
\hline & $6-8$ & $\begin{array}{c}\text { phenol, bisphenol } \\
\text { A, } \\
\text { sulfamethoxazole, } \\
\text { carbamazepine, } \\
\text { pyrimethanil } \\
\end{array}$ & [42] \\
\hline & 6 & urban wastewater & {$[43]$} \\
\hline & 6.8 & imidacloprid & {$[44]$} \\
\hline & $2.8-5$ & textile wastewater & {$[28]$} \\
\hline & $6-7$ & $\begin{array}{l}\text { carbamazepine, } \\
\text { fluomequine, } \\
\text { ibuprofen, } \\
\text { ofloxacin, } \\
\text { sulfamethoxazole } \\
\end{array}$ & [34] \\
\hline & 7 & urban wastewater & {$[45]$} \\
\hline & 6.2 & $\begin{array}{c}\text { 2,2-bis-(4- } \\
\text { hydroxyphenyl) } \\
\text { propane }\end{array}$ & [46] \\
\hline & 6,2 & synthetic mixture & {$[47]$} \\
\hline & 7 & crotamiton & [40] \\
\hline NTA & 7 & sulfamethoxazole & [31] \\
\hline
\end{tabular}

\begin{tabular}{|c|c|c|c|}
\hline \multirow[b]{2}{*}{ dcbpy } & 7 & 2,4-DCP, Orange II & [48] \\
\hline & 6 & $\begin{array}{l}\text { 2,4-Dichlorophenol } \\
\text { Orange } 2\end{array}$ & [49] \\
\hline \multirow[b]{2}{*}{ Humic acids } & 7 & urban wastewater & [45] \\
\hline & 7 & $\begin{array}{c}\text { acetaminophen, } \\
\text { caffeine, } \\
\text { amoxicillin, } \\
\text { clofibric } \\
\text { acid,carbamazepine } \\
\text { and acetamiprid }\end{array}$ & [50] \\
\hline \multirow[t]{2}{*}{ Humic like } & $3-7$ & $\begin{array}{c}\text { acetaminophen, } \\
\text { caffeine, } \\
\text { amoxicillin, } \\
\text { clofibric } \\
\text { acid,carbamazepine } \\
\text { and acetamiprid }\end{array}$ & [51-53] \\
\hline & 7 & Crystal violet & [54] \\
\hline
\end{tabular}

Table 2: Examples of mild photo-Fenton driven in the presence of complexing agents; $\mathrm{pH}$ conditions and treated pollutants are given.

It is well known that iron carboxylates undergo, upon irradiation, ligand to metal charge transfer reaction [55], that enhances the reduction of iron, thus resulting in an acceleration photo-Fenton, in addition to iron stabilization [1, 56]. Furthermore, some of these compounds show stronger absorption band in the UVA-vis and higher quantum yields when compared with iron aquo-complexes. However, the mechanism involves descarboxilation of the ligand, as shown in equation 3, what results in a sacrificial role of the carboxylate that should be added, at least, in stoichiometric amount. Furthermore addition of extra amounts of organic matter to an effluent for detoxification should always be considered a drawback and this amount should be minimized $[31,57]$.

$$
[\mathrm{Fe}(\mathrm{OOC}-\mathrm{R})]^{2+}+\mathrm{h} v \rightarrow \mathrm{Fe}^{2+}+\mathrm{CO}_{2}+\mathrm{R} .
$$

Oxalic acid is the carboxylic compound that has been more widely employed; its molecular weight is very low, and hence the amount of organics per mole is minimized and the byproducts that are generated are not an important concern. Ferrioxalate has been employed to enhance photo-Fenton under simulated sunlight at $\mathrm{pH}=5$. Results were promising, even when scaled up to pilot plant. However high Fe:oxalate molar ratios (from 1:3 to 1:9) were used [29].

Alternatively, other carboxylic acids have also been used. In particular citric acid has been employed to degrade pesticides at several mildly acidic and neutral $\mathrm{pHs}[36,37]$. Also in this case, the mechanism involves a sacrificial role for citrate, as can be observed in Figure 2. Similar processes have been recently described for benzoic acid derivatives, which would help to explain the shifting in reactivity of effluents containing phenolic compounds, as described in the previous section. These species are able to photo-reduce $\mathrm{Fe}(\mathrm{III})$, underdoing a ligand to metal charge transfer reaction that results in descarboxylation of the ligand. Although, aromatics are less efficient than aliphatic carboxylates, this mechanism 
could help to understand the extension of efficient photoFenton domain in effluents rich in phenolic compounds, as described in the previous section [58]

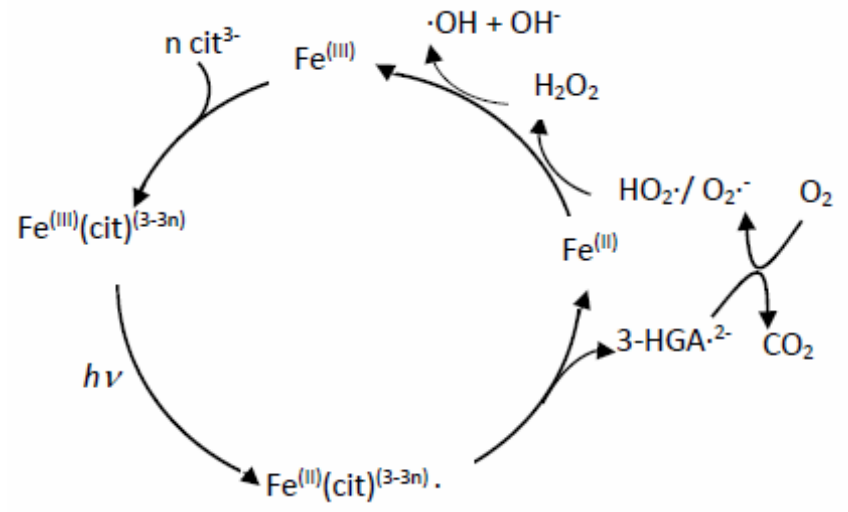

Figure 2: Scheme of the mechanism of the photo-Fenton process driven in the presence of citrate $\left(\mathrm{cit}^{3-}\right)$. Photoreduction of $\mathrm{Fe}$ (III) by citrate results in the formation of 3-hydroxoglutarate radical (3-HGA.2-). Extracted from [37]

Another group of substances used for iron complexation are bidentate chelating agents such as ethylenediaminetetraacetic acid (EDTA), ethylenediamine$\mathrm{N}, \mathrm{N}^{\prime}$-disuccinic acid (EDDS) or nitrilotriacetic acid (NTA). In particular, EDDS was proposed as an auxiliary for mild photoFenton by the research group of Mailhot el al. in 2012 [45], who observed that in the presence of this compound, the removal of bisphenol $\mathrm{A}$, an endocrinal disruptor, could be achieved via photo-Fenton at neutral $\mathrm{pH}$ when irradiated with artificial UVA-vis light. Its performance was compared with other ligands, showing EDDS the best results (Figure 3)

EDDS has received increasing attention and it has been employed to treat deferent effluents and model compounds, using both, lamps and real sunlight. A detailed information on the pollutants that have been studied can be found in Table 2 . Miralles et al. [43] investigated the removal of a mixture of pharmaceuticals at concentrations of a few $\mu \mathrm{g} / \mathrm{L}$ at neutral medium via photo-Fenton under solar irradiation. Citrate and EDDS were used as complexing agents. Both of them were able to enhance the oxidation process although high amount of those chemicals were required, as molar ratios Fe:citrate/EDDS were between 1:1 and 1:5. This resulted in an increase of the amount of hydrogen peroxide consumption. EDDS was also used to remove a set of 46 micropollutants from real and spiked wastewater treatment plant effluents. Results were very encouraging as the concentration of most pollutants quickly fell below the limit of quantitation. However, the process was strongly dependent on the sample matrix (in particular carbonates played an important inhibitory role), and the addition of EDDS resulted in an important increase (ca. 5 times) of the initial DOC [47]). In another paper, those authors compared the performance of photo-Fenton at $\mathrm{pH}=3$ and neutral $\mathrm{pH}$ in the presence of EDDS and humic acids; the target solution was the effluent of a wastewater treatment plant, containing emerging effluents at $\mathrm{ng} / \mathrm{L}$ concentration. Results indicated that $95 \%$ removal was reached in all conditions that were tested, although reaction was faster at $\mathrm{pH}=3$. However, neutral photo-Fenton with EDDS was indicated to be the most convenient, because of the low hydrogen peroxide consumption and the neutral $\mathrm{pH}$ conditions [45].

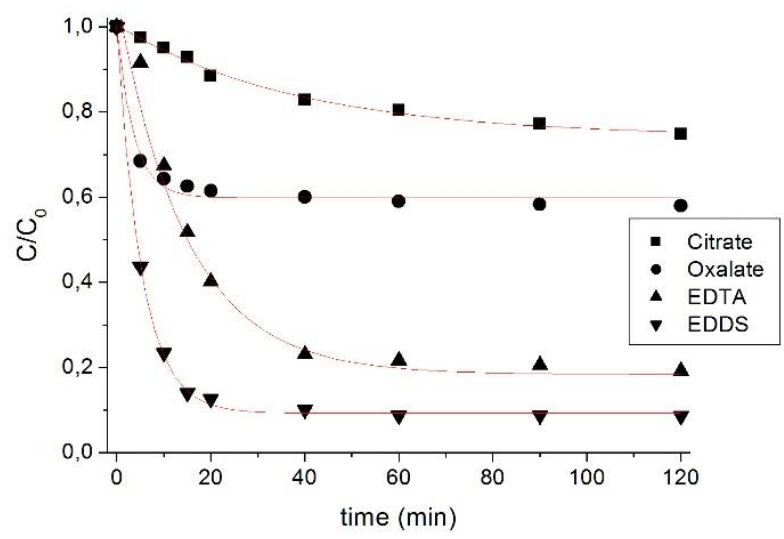

Figure 3: Effect of different iron(III) complexes on the degradation of bisphenol $\mathrm{A}$ at $\mathrm{pH}=6.2$.

NTA has been employed to treat sulfamethoxazole, a widely used antibiotic, at $\mathrm{pH}=7$ [34]. Its performance has been compared with other ligands, namely tartaric acid, oxalic acid and EDTA. As shown in Figure 4, best results were reached with EDTA and NTA, as higher percentages of antibiotic photodegradation has been reached with lower addition of organics that with tartaric acid and oxalic acid. However, authors the better biodegradability of NTA vs. EDTA makes the first one a better chemical auxiliary. Another work from the same research group has been devoted to study the stability of the Fe-NTA complex under the conditions of irradiation [59]. 


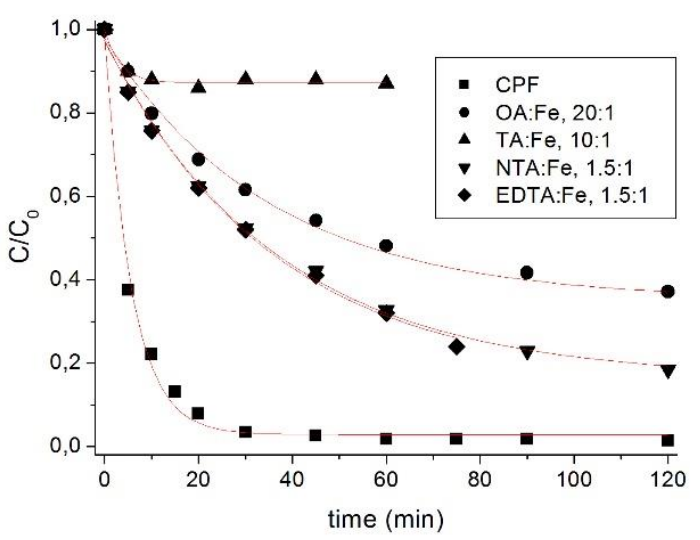

Figure 4: Sulfamethoxazole $(0.079 \mathrm{mM})$ removal by photoFenton-like at neutral $\mathrm{pH}$ with $\mathrm{Fe}(\mathrm{III})$ chelates, In all cases $\left[\mathrm{Fe}^{3+}\right]_{0}=0.089 \mathrm{mM}$ and $\left[\mathrm{H}_{2} \mathrm{O}_{2}\right]_{0}=0.294 \mathrm{mM}$. The studied conditions were: a) EDTA:Fe(III) $=1.5: 1(\mathrm{pH}=7.0 \pm 0.7)$, b) NTA:Fe(III) $=1.5: 1(\mathrm{pH}=7.0 \pm 0.7), \mathrm{c})$ tartaric acid:Fe(III) $=10: 1(\mathrm{pH}=7.0 \pm 0.15), \mathrm{d})$ oxalic acid:Fe(III) $=20: 1(\mathrm{pH}=$ $7.0 \pm 0.15)$ e) SMX removal by conventional photo-Fenton $(\mathrm{CPF}) ; \mathrm{pH}=2.7 \pm 0.1$ ). Extracted from [34]

Macromolecules can also be used as complexing agent. Because of its high molecular weight, they have a high number of active sites per molecule and, if they suffer oxidation, some of those groups might be destroyed, but they could be replaced by others newly formed; hence, these substances are expected to be more resistant towards oxidation and to avoid the loss of efficiency observed in the photo-Fenton process in smaller molecules.

Humic substances are good complexing agents for iron in the environment, and in fact, photo-Fenton-like process mediated by those complexes have been reported as an important pathway for the removal of xenobiotics in aquatic ecosystems [60]. Vermilyea and Volker demonstrated that natural sources of iron and humic substances are able to drive photo-Fenton process, although different mechanism mechanistic pathways are involved [61]. In fact, experiments with fulvic acids indicated that these substances had an important influence in the redox cycle of iron, able to photoreduce $\mathrm{Fe}(\mathrm{III})$ as carboxylates, in a reaction that is faster at $\mathrm{pH}=5$ [62]. Based on these results, some authors have studied the possibility of driving mimetic processes in the laboratory, showing that humic substances-iron-hydrogen peroxide are able to enhance photodegradation of pharmaceuticals and pesticides at $\mathrm{pH}=7$ under simulated sunlight $[45,50]$. However, the process was still too slow to be applied in real situations.

Substances with similar characteristics as humic acids can be isolated from different sources, such as urban wastes [63]. They are obtained following a procedure that involves basic digestion of the composted waste, filtration to remove the insoluble fraction and a membrane process to concentrate the humic substances in the retentate, that are obtained upon evaporation of the solvent. This assembly of macromolecules have been named as "soluble bio-organic" substances (SBO) or humic-like substances (HLS). As shown in Table 2, a series of papers has been published in recent years reporting on the ability of these substances to drive circumneutral photoFenton. Results were strongly dependent on the experimental conditions as opposite factors are involved, the most important of which are: a) an improved generation of reactive species via photo-Fenton, $b$ ) the screen effect due to the colour of SBO, c) a competitive effect SBO-pollutant for the reactive species and d) the surfactant properties of SBO. Experimental design methodology have demonstrated that the $\mathrm{pH}$ domain were photo-Fenton can be applied is extended to $\mathrm{pH}$ ca. 5, beyond this point, there is a noticeable loss of efficiency (See Figure 5). Optimal concentrations of SBO were typically 10$20 \mathrm{mg} / \mathrm{L}$ and a low concentration of iron is required (3-5 $\mathrm{mg} / \mathrm{L}$ ) [52].

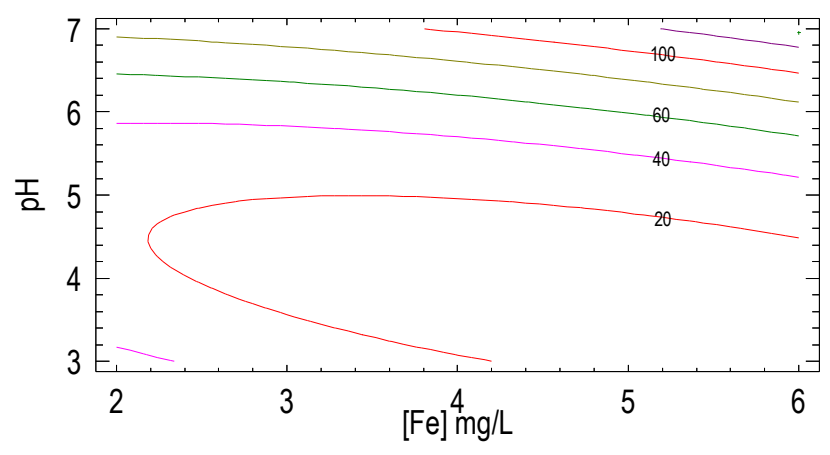

Figure 5: Contour plots for the time (min) the initial concentration of carbamazepine required to reduce to a $50 \%$ by a photo-Fenton process. The concentration of SBO was 25 $\mathrm{mg} / \mathrm{L}$ and that of carbamazepine was $5 \mathrm{mg} / \mathrm{L}$. Adapted from [52]

SBO are relatively stable towards chemical oxidation and no significant loss of efficiency can was observed along photo-Fenton. Different bioassays have demonstrated that those compounds are non-toxic and scarcely biodegradable [53]. Finally experiments have been driven with real sunlight at $\mathrm{pH}=5.2$.

\section{PROCESS HETEROGENEIZATION}

A very different strategy to drive photo-Fenton at neutral medium consists in using an active iron-containing solid surface, which can be iron-based minerals, iron coated particles or immobilized active iron species onto solid supports. Although this procedure has been mainly employed in Fenton processes, most probably due to scattering of light by the solid species, some examples can be found in literature on their application to photo-Fenton [64-92]. However, it has to be indicated that most papers are focused on the synthesis and characterization of the solid materials and they just provide one or two examples of their performance using model compounds. 
A group of heterogeneous catalysts is composed by ironcontaining minerals. Among them, iron oxides such as hematite, goethite or magnetite have been employed [64-71]. Figure 6 shows the rate constants determined for the removal of orange II in the presence of different oxides; interestingly, best results were reached with ferrihydrite, followed by maghemite which were the materials which produced higher $\mathrm{pH}$ decreases. Hence, $\mathrm{pH}$ might be important also in heterogeneous photo-Fenton; this could be due to iron leaching, more likely at lower $\mathrm{pH}$, as indicated below. In some cases, these oxides are micro or nanoparticulated. In addition to this, hybrid oxides containing other metals have also been used. [72-77]. In this case, the leaching of toxic heavy metals constitutes a major concern.
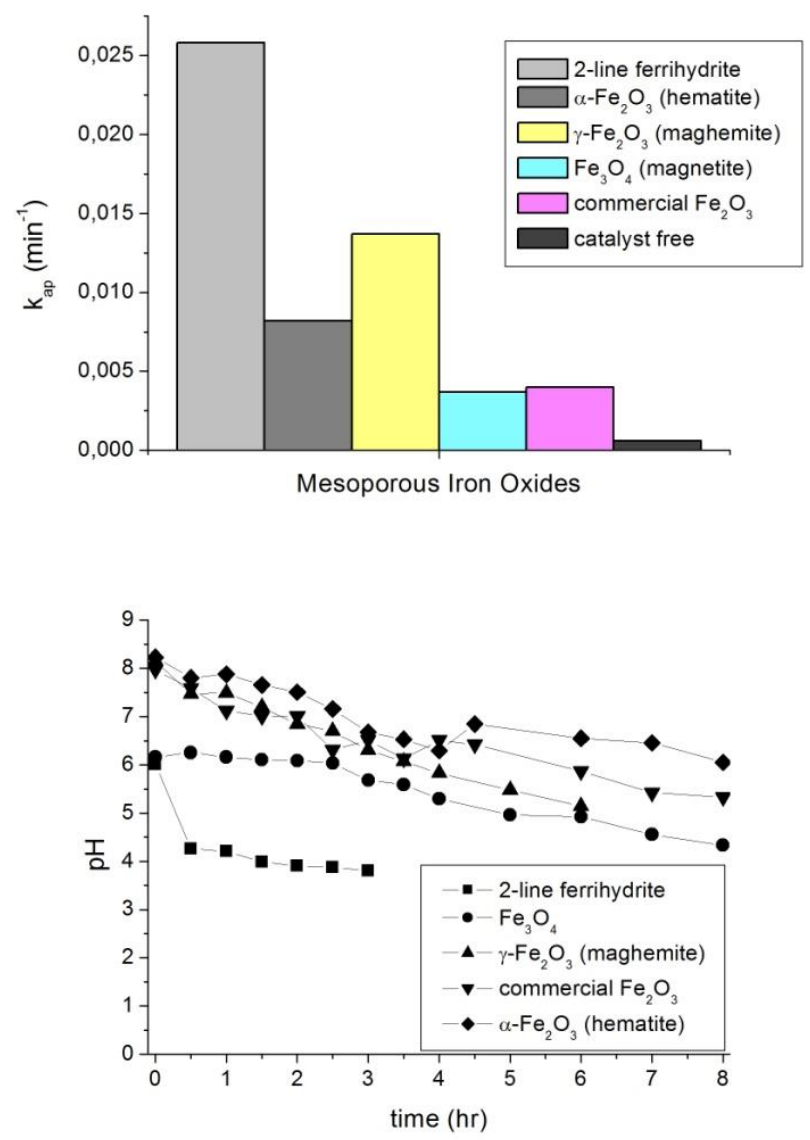

Figure 6: Above: Rate constants determined in the photoFenton decolorization of orange II in the presence of different iron minerals. Below: $\mathrm{pH}$ variation in the experiments. Adapted from [70].

Iron has be supported onto different materials such as zeolites [78-80], clays such as montmorillonite [81, 82] carbonous materials [83-86], membranes [87- 89], resins [68] alginate [82] or silica [90]. Supporting iron onto adsorbents such as clays, zeolites or activated carbon seems meaningful in view of using photo-Fenton as a treatment for the regeneration of these materials. A similar strategy can be used with membranes, where photo-Fenton can be used to prevent fouling or to treat retentate.
Some hybrid materials have also been employed: for instance, an iron mineral, $\alpha-\mathrm{FeOOH}$ has been supported onto an ion exchange resin, namely amberlite, to treat $17 \beta$-estradiol under $\mathrm{UV}$ irradiation. Although reaction was faster at $\mathrm{pH}=3$, photo-Fenton was still very efficient at $\mathrm{pH}$ as high as 11 . Some iron leaching was observed, although concentration of iron is solution was systemically below $1 \mathrm{mg} / \mathrm{L}$ [68]

In fact, In some cases the real photo-Fenton process is attributable to a fraction of iron that remains in the solution. For instance, carboxylates are known to drive a photochemical process that solubilizes iron (III) present in heterogeneous or colloidal medium by means of a mechanism that involves reduction to soluble $\mathrm{Fe}$ (II) species [91]. Demarchis et al. when studying the removal of phenol by photo-Fenton in the presence of hematite as iron source observed leaching of small amounts of iron that might be responsible for the process via a homogeneous photo-Fenton [92]. However, this should not be considered as a major drawback from the practical point of view as the amount of iron present in the solution is commonly well below the limits set by legislation.

\section{5. "IN SITU" GENERATION OF IRON}

A possibility to overcome the inconvenience of iron inactivation at neutral medium is continuous release of active iron(II) or iron(III) species into the solution. As indicated in the previous section, solid iron-containing materials release iron cations into solution, which are able to drive photoFenton. although in most papers researchers try to minimize this effect in order to drive heterogeneous photo-Fenton, in a few recent papers leaching of iron is favoured to drive homogeneous neutral photo-Fenton. However, as hapenned with heterogeneus processes, this strategy has been more widely applied in dark Fenton, because of the more difficult illumination of a solution containing solid particles [93-95].

The most widely employed strategy is the corrosion of zero valent iron (ZVI) [96]. However, recently, some authors have investigated to employ also the ability of ZVI to act as reductive agent. For this purpose, the process is driven with and without hydrogen peroxide. The reductive step is commonly employed to remove deactivating functional groups, namely nitroaromatics $[97,98]$. Then, addition of hydrogen peroxide and irradiation (photo-Fenton step) is used to deal with the more easily oxidizable aminoaromatics. Figure 7 shows reduction of 4-nitrobenzoic acid by means of an iron wool to give 4-aminobenzoic acid; then, hydrogen peroxide was added and illumination began to drive a photoFenton with the iron released in the previous step. 


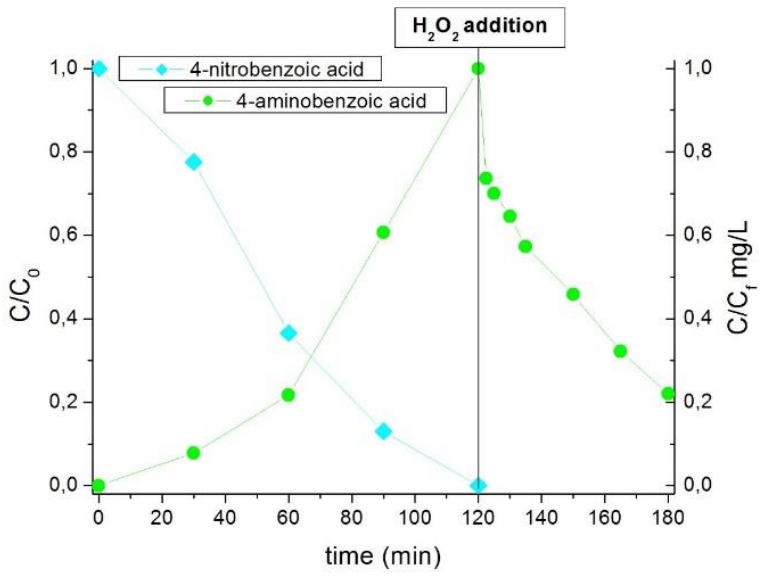

Figure 7: Plot of the relative concentration of 4-nitrobenzoic acid and 4-aminobenzoic acid along a combined process consisting a reductive phase (ZVI) followed by an oxidation (photo-Fenton) upon $\mathrm{H}_{2} \mathrm{O}_{2}$ addition. Taken from [97].

Also metallurgical slags have been employed as a source of photo-Fenton-like photocatalysts; Arzate Salgado et al., used copper and steels slags to treat diclofenac under simulated sunlight (Xenon lamp) at $\mathrm{pH}=7$; although results did not improve dramatically the effect of hydrogen peroxide, most probably because the astringent $\mathrm{pH}$ conditions, some effect was observed. [99]. Other authors drive similar processes with other metals, such as copper, although again in thi case the toxicity of this heavy metal is a concern [100].

Iron minerals (e.g. goethite) can also be employed as a source of iron. Huang et al. published an interesting article in which combined this approach with the use of chelating agents. This system is highly dependent on reaction condition as opposite effects are found: surface inactivation by deposition of EDDS, which decreases heterogeneous photoFenton and enhancement of the homogeneous process because of iron stabilization by EDDS. As consequence, an optimum pH 06.7 was found for the degradation of bisphenol A with UVA-visible light (fluorescent tubes which irradiate in the $300-500 \mathrm{~nm}$ range) [69]

\section{CONCLUSIONS}

Shifting experimental conditions towards milder $\mathrm{pH}$ values is receiving increasing attention from researchers in the last decade. Different approaches have been used for this purpose, as indicated above, and each one seems meaningful for some niche application:

a) Using low concentrations of iron might be interesting to deal surfactants at trace amounts, such as xenobiotics at the effluents of wastewater treatment plants, as even inefficient generation of reactive species might be enough to remove those toxicants. b) Investigation of the optimum $\mathrm{pH}$ when dealing with a new effluent is a meaningful task as it should not be taken for granted that a $\mathrm{pH}=2.8$ is the optimum for photo-Fenton. In fact, the presence of species able to complex iron could be rather common, and slight increases in working $\mathrm{pH}$ might represent significant savings.

c) The use of complexing agents is able to extend the range of application of photo-Fenton to $\mathrm{pH}$ values close to 5. This would allow the removal of target highly toxic pollutants, where addition of extra amounts of DOC is not a problem. Carboxylates or chelating agents such as EDDS or NTA have demonstrated to drive an efficient photo-Fenton. In this context, the use of non-toxic sustainable sources of complexing agents such as humic-(like) substances should be investigated, as they can be considered as a green process.

d) Heterogeneization of the process might be useful for some purposes, such as prevent fouling of membranes via supporting iron in their structure or regeneration of adsorbent materials. Iron containing nanoparticles could also allow using iron concentrations above the limits of discharge, recycling of the catalyst or an easy removal after the reaction. Although it is not a major drawback for application, solubilized iron might be responsible for the photo-Fenton process.

e) The use of elemental iron can employed to combine reducing with oxidizing steps, what is interesting to treat those compounds difficult to oxidize. Using other solid sources can be used to dose iron at low amounts, although this approach is limited by higher hydrogen peroxide requirements or scattering of light by the solid particles.

Nonetheless, much effort is still needed, on this issue. For instance, some of the approaches are very recent and hence their real applicability is not established yet, such as the $\mathrm{ZVI} /$ photo-Fenton coupling or determination of the optimum $\mathrm{pH}$ for photo-Fenton in complex effluents; in other cases, there are important drawbacks that should be overcome (for instance decreasing the amount of complexing agents, when they are employed, or stability of supported heterogeinized photocatalysts).

Furthermore most experiments have been carried out with model compounds at concentrations $(\mathrm{mg} / \mathrm{L})$ far above for those commonly found in those effluents that can be potentially treated, using distilled water as solvent; this is an important problem because the important effect of the matrix (e.g carbonates or dissolved organics) cannot be determined and significant parameters such as hydrogen peroxide amount or optimal complexing agent concentration cannot be determined. This might be due to the complex analytical tools required to monitor real systems.

Finally, mechanistic issues still remain uncertain. The complex manifold of equations involved in "classical" photoFenton becomes even more complex with the addition of new species or different experimental conditions that results in changes in the coordination sphere of iron. Hence alternative processes such ligand to metal charge transfer reaction, the involvement of excited states of organic molecules or the 
presence of different oxidation of iron might result in the occurrence of new reaction pathways or the involvement of other reactive species rather than hydroxyl radical.

\section{CONFLICT OF INTEREST}

This work was done with the financial of the Marie Sklodowska-Curie Research and Innovation Staff Exchange project funded by the European Commission H2020-MSCARISE-2014, within the framework of the research project Mat4treat. Authors also want to thank the financial support of Spanish Ministerio of Economía y Competitividad (TRICERATOPS project and FOTOCAT excellence network).

\section{ACKNOWLEDGEMENTS}

All the three authors have collaborated in the preparation of this work.

\section{REFERENCES}

[1] Pignatello J.J., Oliveros E., MacKay A., Advanced oxidation processes for organic contaminant destruction based on the Fenton reaction and related chemistry. Crit. Rev. Environ. Sci. Technol., 2006, 36, 1-84.

[2] Pignatello J.J. Dark and photoassisted $\mathrm{Fe}^{3+}$-catalyzed degradation of chlorophenoxy herbicides by hydrogen peroxide. Environ. Sci. Technol., 1992, 26, 944-951.

[3] Sánchez Pérez J.A., Román Sánchez I.M., Carra I., Cabrera Reina A., Casas López J.L., Malato S., Economic evaluation of a combined photo-Fenton/MBR process using pesticides as model pollutant. Factors affecting costs. J. Hazard. Mater., 2013, 244-245, 195-203.

[4] Bokare A.D., Choi W. Review of iron-free Fenton-like systems for activating $\mathrm{H}_{2} \mathrm{O}_{2}$ in advanced oxidation processes. J. Hazard. Mater., 2014, 275, 121-135.

[5] Brillas, E.; Sirés, I.; Oturan, M. A. Electro-Fenton process and related electrochemical technologies based on Fenton's reaction chemistry. Chem. Rev., 2009, 109, 6570-6631.

[6] Ruales-Lonfat C., Barona J.F., Sienkiewicz A., Velez J., Benitez L.N., Pulgarin C. Bacterial inactivation with iron citrate complex: A new source of dissolved iron in solar photo-Fenton process at nearneutral and alkaline pH. Appl. Catal. B-Environ., 2016, 180, 379390.

[7] Ortega-Gomez E., Martin M.M.B., Garcia B.E., Perez J.A.S., Ibanez P.F. Wastewater disinfection by neutral $\mathrm{pH}$ photo-Fenton: The role of solar radiation intensity. Appl. Catal. B-Environ., 2016, 181, 1-6.

[8] Miralles-Cuevas S., Oller I., Perez J.A.S., Malato S. Application of solar photo-Fenton at circumneutral $\mathrm{pH}$ to nanofiltration concentrates for removal of pharmaceuticals in MWTP effluents. Environ. Sci. Pollut. Res., 2014, 22 (2), 846-855.

[9] Neamtu M., Grandjean D., Sienkiewicz A., Le Faucheur S., Slaveykova V., Colmenares J.J.V., Pulgarin C., De Alencastro L.F. Degradation of eight relevant micropollutants in different water matrices by neutral photo-Fenton process under UV254 and simulated solar light irradiation - A comparative study. Appl. Catal. B-Environ., 2014, 158-159, 30-37.

[10] De la Cruz N., Esquius L., Grandjean D., Magnet A., Tungler A., de Alencastro L.F., Pulgarin C. Degradation of emergent contaminants by $\mathrm{UV}, \mathrm{UV} / \mathrm{H}_{2} \mathrm{O}_{2}$ and neutral photo-Fenton at pilot scale in a domestic wastewater treatment plant. Water Res., 47 (15), 2013, 5836-5845.

[11] Klamerth N., Malato S., Aguera A., Fernandez-Alba A. PhotoFenton and modified photo-Fenton at neutral $\mathrm{pH}$ for the treatment of emerging contaminants in wastewater treatment plant effluents: A comparison. Water Res., 2013, 47 (2), 833-840.

[12] Bernabeu A., Palacios S., Vicente R., Vercher R.F., Malato S., Arques A., Amat A.M. Solar photo-Fenton at mild conditions to treat a mixture of six emerging pollutants. Chem. Eng. J., 2012,198-199, $65-72$.

[13] De la Cruz N., Gimenez J., Esplugas S., Grandjean D., De Alencastro L.F., Pulgarin C. Degradation of 32 emergent contaminants by UV and neutral photo-fenton in domestic wastewater effluent previously treated by activated sludge. Water Res., 2012, 46 (6), 1947-1957.

[14] Moncayo-Lasso A., Rincon A.-G., Pulgarin C., Benitez N Significant decrease of THMs generated during chlorination of river water by previous photo-Fenton treatment at near neutral $\mathrm{pH}$. Journal of Photochemistry and Photobiology A: Chemistry, 2012, 229 (1), 46-52.

[15] Bernabeu A., Vercher R.F., Santos-Juanes L., Simon P.J., Lardin C., Martinez M.A., Vicente J.A., Gonzalez R., Llosa C., Arques A., Amat A.M. Solar photocatalysis as a tertiary treatment to remove emerging pollutants from wastewater treatment plant effluents. Catal. Today, 2011,161 (1), 235-240.

[16] Sun M., Zhao Y.-S., Dong J., Dong L.-L. Study on degradation of nitrobenzene in groundwater by Fenton-like oxidation based on iron in aquifer materials. Adv. Mat. Res., 2011, 183-185, 516-521.

[17] Klamerth, N., Rizzo, L.; Malato, S.; Maldonado, M.I.; Agüera, A.; Fernández-Alba A.R. Degradation of fifteen emerging contaminants at $\mu \mathrm{g} \mathrm{L-1}$ initial concentrations by mild solar photo-Fenton in MWTP effluents. Water Res., 2010, 44, 545 - 554.

[18] Barona J.F., Morales D.F., González-Bahamón L.F., Pulgarín C. Benítez L.N., Shift from heterogeneous to homogeneous catalysis during resorcinol degradation using the solar photo-Fenton process initiated at circumneutral pH. Appl. Catal. B-Environ., 2015, 165, 620-627

[19] Carra I., Casas Lopez J.L., Santos-Juanes L., Malato S., Sanchez Perez J.A. Iron dosage as a strategy to operate the photo-Fenton process at initial neutral pH. Chem. Eng. J., 2013, 224 (1), pp. 67-74 [Brillas] Brillas,E.; Sirés, I.; Oturan, M. A. Electro-Fenton process and related electrochemical technologies based on Fenton's reaction chemistry. Chem. Rev. 2009, 109, 6570-6631

[20] García-Ballesteros, S.; Mora, M.; Vicente, R.; Sabater, C.; Castillo, M.A.; Arques, A.; Amat, A.M... Gaining further insight into photoFenton treatment of phenolic compounds commonly found in food processing industry. Chem Eng. J. 2016, 288, 126-136.

[21] Moncayo-Lasso, A.; Pulgarin, C.; Benítez, N. Degradation of DBPs' precursors in river before and after sand filtration by photo-Fenton process at $\mathrm{pH}=5$ in a solar CPC reactor. Water Res. 2008, 42, 41254132

[22] Katsumata, H.; Sada, M.; Kaneco, S.; Suzuki, T.; Ohta, K.; Yobiko, Y. Humic acid degradation in aqueous solution by photo-Fenton process. Chem Eng. J. 2008, 137, 225-230.

[23] Santos-Juanes L., Amat A.M., Arques A., Bernabeu A., Silvestre M., Vicente R., Añó E., Activated sludge respirometry to assess solar detoxification of a metal finishing effluent. J. Hazard. Mat., 2008, 153, 905-910.

[24] Gutiérrez-Zapata, H.M.; Rojas, K.L.; Sanabria, J.; Rengifo-Herrera, J.A. 2,4-D abatement from groundwater samples by photo-Fenton processes at circumneutral $\mathrm{pH}$ using naturally iron present. Effect of inorganic ions. Environ Sci Pollut Res. 2016. doi:10.1007/s11356016-7067-5

[25] Conte L.O., Schenone A.V., Alfano O.M. Photo-Fenton degradation of the herbicide 2,4-in aqueous medium at $\mathrm{pH}$ conditions close to neutrality. J. Environ. Manage., 2016, 170, 60-69.

[26] Conte L.O., Schenone A.V., Alfano O.M. Ferrioxalate-assisted solar photo-Fenton degradation of a herbicide at $\mathrm{pH}$ conditions close to neutrality. Environ. Sci. Pollut. Res, 2016, 1-8. Article in Press. 
[27] Souza B.M., Marinho B.A., Moreira F.C., Dezotti M.W.C., Boaventura R.A.R., Vilar V.J.P. Photo-Fenton oxidation of 3-amino5-methylisoxazole: a by-product from biological breakdown of some pharmaceutical compounds. Environ. Sci. Pollut. Res., 2015, Article in Press.

[28] Soares P.A.; Batalha M.; Souza S.M.A.G.U.; Boaventura R.A.R.; Vilar V.J.P. Enhancement of a solar photo-Fenton reaction with ferric-organic ligands for the treatment of acrylic-textile dyeing wastewater. J. Environ. Manage 2015, 152, 120-131.

[29] Souza B.M., Dezotti M.W.C., Boaventura R.A.R., Vilar V.J.P. Intensification of a solar photo-Fenton reaction at near neutral $\mathrm{pH}$ with ferrioxalate complexes: A case study on diclofenac removal from aqueous solutions. Chem. Eng. J., 2014,256, pp. 448-457.

[30] Pereira J.H.O.S., Queiros D.B., Reis A.C., Nunes O.C., Borges M.T., Boaventura R.A.R., Vilar V.J.P. Process enhancement at near neutral $\mathrm{pH}$ of a homogeneous photo-Fenton reaction using ferricarboxylate complexes: Application to oxytetracycline degradation. Chem. Eng. J., 2014, 253, 217-228.

[31] De Luca, A.; Dantas, R.F.; Esplugas, S. Assessment of iron chelates efficiency for photo-Fenton at neutral pH. Water Res. 2014, 61, 232242 .

[32] Dias I.N., Souza B.S., Pereira J.H.O.S., Moreira F.C., Dezotti M., Boaventura R.A.R., Vilar V.J.P. Enhancement of the photo-Fenton reaction at near neutral $\mathrm{pH}$ through the use of ferrioxalate complexes: A case study on trimethoprim and sulfamethoxazole antibiotics removal from aqueous solutions. Chem. Eng. J., 2014, 247, 302-313.

[33] Xue X., Liu Y., Shao Y., Deng N. Rapid decolorization of rhodamine B by UV/Fe(III)-penicillamine process under neutral $\mathrm{pH}$ : Compared with UV/Fe(III)-oxalate. Adv. Mater. Res., 2011, 183-185, pp. 130134.

[34] Miralles-Cuevas S., Oller I., Perez J.A.S., Malato S. Removal of pharmaceuticals from MWTP effluent by nanofiltration and solar photo-Fenton using two different iron complexes at neutral $\mathrm{pH}$. Water Res., 2014, 64, 23-31.

[35] Katsumata, H.; Kaneco, S.; Suzuki, T.; Ohta, K.; Yobiko, Y. PhotoFenton degradation of alachlor in the presence of citrate solution. $J$. Photochem. Photobiol. A: Chem. 2006, 180, 38-45

[36] Silva, M.R.A.; Trovo, A.G.; Nogueira, R.F.P. Degradation of the herbicide tebuthiuron using solar photo-Fenton process and ferric citrate complex at circumneutral pH. J. Photochem. Photobiol. A: Chem. 2007, 191, 187-192.

[37] Ou, X.; Quan, X.; Chen, S.; Zhang, F.; Zhao, Y. Photocatalytic reaction by $\mathrm{Fe}(\mathrm{III})-$ citrate complex and its effect on the photodegradation of atrazine in aqueous solution. J. Photochem. Photobiol. A: Chem. 2008, 197, 382-388

[38] Carra I., Malato S., Santos-Juanes L., Casas Lopez J.L., Sanchez Perez J.A. Study of iron sources and hydrogen peroxide supply in the photo-Fenton process using acetaminophen as model contaminant. J. Chem. Technol. Biotechnol., 2013, 88, 636-643.

[39] Wang Z., Guo Y., Liu Z., Feng X., Chen Y., Tao T. Catechin as a new improving agent for a photo-Fenton-like system at near-neutral $\mathrm{pH}$ for the removal of inderal. Photochem. Photobiol. Sci., 2015, 14, 473-480.

[40] Li, Y.; Sun, J.; Sun; S.P. $\mathrm{Mn}^{2+}$-mediated homogeneous Fenton-like reaction of Fe(III)-NTA complex for efficient degradation of organic contaminants under neutral conditions. J. Hazard. Mater. 2016, 313, $193-200$

[41] Wei C.S., Huang W.Y., Zhang R.J., Wang Y.H., Luo L.M., Mo H., Xiao L.H. Assessment of the fe3+-EDTA complex in UV-FentonLike processes: The degradation of methylene blue. Appl. Mech. Mater., 2014, 675-677, 395-400.

[42] Papoutsakis, S.; Miralles-Cuevas, S.; Oller, I., Garcia Sanchez,J.L.; Pulgarin, C.; Malato S. Microcontaminant degradation in municipal wastewater treatment plant secondary effluent by EDDS assisted photo-Fenton at near-neutral $\mathrm{pH}$ : An experimental design approach. Catal. Today, 2015, 252, 61-69.
[43] Miralles-Cuevas S., Oller I., Aguera A., Ponce-Robles L., Perez J.A.S., Malato S. Removal of microcontaminants from MWTP effluents by combination of membrane technologies and solar photoFenton at neutral pH. Catal. Today, 2015, 252, 78-83.

[44] Papoutsakis S., Brites-Nobrega F.F., Pulgarin C., Malato S. Benefits and limitations of using $\mathrm{Fe}$ (III)-EDDS for the treatment of highly contaminated water at near-neutral pH. J. Photochem. Photobiol., A, 2015, 303-304, 1-7.

[45] Klamerth N., Malato S., Aguera A., Fernandez-Alba A. PhotoFenton and modified photo-Fenton at neutral $\mathrm{pH}$ for the treatment of emerging contaminants in wastewater treatment plant effluents: A comparison. Water Res., 2013, 47 (2), 833-840.

[46] Huang W., Brigante M., Wu F., Hanna K., Mailhot G. Development of a new homogenous photo-Fenton process using Fe(III)-EDDS complexes. J. Photochem. Photobiol., A, 2012, 239, 17-23.

[47] Klamerth N., Malato S., Aguera A., Fernandez-Alba A., Mailhot G. Treatment of municipal wastewater treatment plant effluents with modified photo-fenton as a tertiary treatment for the degradation of micro pollutants and disinfection. Environ. Sci. Technol., 2012, 46 (5), 2885-2892.

[48] Chen X., Ma W., Li J., Wang Z., Chen C., Ji H., Zhao J. Photocatalytic oxidation of organic pollutants catalyzed by an iron complex at biocompatible $\mathrm{pH}$ values: Using $\mathrm{O}_{2}$ as main oxidant in a fenton-like reaction. J. Phys. Chem. C, 2011, 115 (10), 4089-4095.

[49] Sun C., Chen C., Ma W., Zhao J. Photodegradation of organic pollutants catalyzed by iron species under visible light irradiation Phys. Chem. Chem. Phys., 2011, 13 (6), 1957-1969

[50] Bernabeu, A.; Palacios, S.; Vicente, R.; Vercher, R.F.; Malato, S.; Arques, A.; Amat. A.M. Solar photo-Fenton at mild conditions to treat a mixture of six emerging pollutants, Chem Eng. J. 2012, 198199, 65-72.

[51] Gomis, J.; Bianco Prevot, A.; Montoneri, E.; González, M.C.; Amat, A.M.; Mártire, D.O.; Arques, A.; Carlos, L. Waste sourced biobased substances for solar-driven wastewater remediation: Photodegradation of emerging pollutants, Chem. Eng. J. 2014, 235, 236-243.

[52] Gomis, J.;. Carlos, L.; Bianco Prevot, A.; Teixeira, A.C.S.C.; Mora, M.; Amat, A.M.; Vicente, R.; Arques, A. Bio-based substances from urban waste as auxiliaries for solar photo-Fenton treatment under mild conditions: optimization of operational variables. Catal. Today, 2015, 240, 39-45.

[53] Gomis, J.; Gonçalves, M. G.; Vercher, R. F.; Sabater, M. C.; Castillo, M. A.; Bianco Prevot, A.; Amat, A. M.; Arques, A.. Determination of photostability, biocompatibility and efficiency as photo-Fenton auxiliaries of three different types of soluble bio-based substances (SBO). Catal Today 2015, 252, 177-183.

[54] 5. J. Gomis, R.F. Vercher, A.M. Amat, D.O. Mártire, M.C González, A. Bianco Prevot, E. Montoneri, A. Arques, L. Carlos Application of soluble bio-organic substances (SBO) as photocatalysts for wastewater treatment: Sensitizing effect and photo-Fenton-like process. Catalysis Today, 209 (2013) 176-180

[55] Weller, C.; Horn, S.; Herrmann, H. Photolysis of Fe(III) Carboxylato Complexes: $\mathrm{Fe}$ (II) Quantum Yields and Reaction Mechanisms. $J$. Photochem. Photobiol. A 2013, 268, 24-36.

[56] Zhou D., Huang W., Xu D. Application of carboxylic acids in photoFenton-like systems for the removal of contaminants. Res. J. Chem. Environ., 2014, 18 (9), 73-82.

[57] Malato, S.; Fernández-Ibáñez, P.; Maldonado, M.I.; Blanco, J., Gernjiak, W.. Decontamination and disinfection of water by solar photocatalysis: recent overview and trends. Catal. Today 2009, 147, $1-59$.

[58] Nichela, D.A.; Donadelli, J.A.; Caram, B.F.; Haddou, M.; Rodriguez Nieto, F.J.; Oliveros, E.; García Einschlag, F.S. Iron cycling during the autocatalytic decomposition of benzoic acid derivatives by Fenton-like and photo-Fenton techniques. Appl. Catal. B: Environ. 2015, 170-171, 312-321 
[59] De Luca A., Dantas R.F., Esplugas S. Study of Fe(III)-NTA chelates stability for applicability in photo-Fenton at neutral $\mathrm{pH}$ Appl. Catal. B- Environ., 2015,179, 372-379.

[60] Vione, D.; Minella, M.; Maurino, V.; Minero, C. Indirect photochemistry in sunlit surface waters: photoinduced production of reactive transient species. Chem. Eur. J. 2014, 20, 10590-10606.

[61] Vermilyea, A.W.; Voelker, B.M. .Photo-Fenton reaction at near neutral pH, Environ. Sci. Technol. 2009, 43, 6927-6933.

[62] Voelker, B.M.; Sulzberger, B. Effects of fulvic acid on Fe(II) oxidation by hydrogen peroxide, Environ. Sci. Technol. 1996, 30 1106-1114.

[63] Montoneri, E.; Mainero, D.; Boffa, V.; Perrone. D.G.; Montoneri, C. Biochemenergy: a project to turn an urban wastes treatment plant into biorefinery for the production of energy, chemicals and consumer's products with friendly environmental impact. Int. J. Global Environ Issues 2011, 11, 170-196

[64] Wang Y., Sun Y., Li W., Tian W., Irini A. High performance of nanoscaled $\mathrm{Fe} 2 \mathrm{O} 3$ catalyzing UV-Fenton under neutral condition with a low stoichiometry of $\mathrm{H}_{2} \mathrm{O}_{2}$ : Kinetic study and mechanism. Chem. Eng. J., 2015, 267, 1-8.

[65] $\mathrm{Li}$ W., Wang Y., Irini A.Effect of $\mathrm{pH}$ and $\mathrm{H}_{2} \mathrm{O}_{2}$ dosage on catechol oxidation in nano-Fe3O4 catalyzing UV-Fenton and identification of reactive oxygen species. Chem. Eng. J., 2014, 244, 1-8.

[66] Minella M., Marchetti G., De Laurentiis E., Malandrino M., Maurino V., Minero C., Vione D., Hanna K. Photo-Fenton oxidation of phenol with magnetite as iron source. Appl. Catal. B-Environ., 2014, 154-155, pp. 102-109.

[67] Luo Z., Tang H., Qu L., Han T., Wu X. A visible-light-driven solid state photo-Fenton reagent based on magnetite/carboxylate-rich carbon spheres. CrystEngComm, 2012, 14), 5710-5713.

[68] Yaping, Z; Jiangyong, H. Photo-Fenton degradation of $17 \beta$ estradiol in presence of $\alpha-\mathrm{FeooH}$ and $\mathrm{H}_{2} \mathrm{O}_{2}$. Appl. Catal. B: Environ. 2008, 78, 250-258.

[69] Huang, W.; Brigante, M.; Wu, F.; Hanna, K.; Mailhot, G. Effect of ethylenediamine-N,N'-disuccinic acid on Fenton and photo-Fenton processes using goethite as an iron source: optimization of parameters for bisphenol A degradation. Environ. Sci. Pollut. Res., 2013, 20, 39-50

[70] Jiang T., Poyraz A.S., Iyer A., Zhang Y., Luo Z., Zhong W., Miao R., El-Sawy A.M., Guild C.J., Sun Y., Kriz D.A., Suib S.L. Synthesis of mesoporous iron oxides by an inverse micelle method and their application in the degradation of orange II under visible light at neutral pH. J. Phys. Chem. C, 2015, 119 (19), 1045410468

[71] Nie Y., Hu C., Zhou L., Qu J., Wei Q., Wang D. Degradation characteristics of humic acid over iron oxides/ $\mathrm{Fe} 0$ core-shell nanoparticles with UVA/H2O2. J. Hazard. Mater., 2010, 173 (1-3), pp. $474-479$

[72] Chai F., Li K., Song C., Guo X. Synthesis of magnetic porous $\mathrm{Fe} 3 \mathrm{O} 4 / \mathrm{C} / \mathrm{Cu} 2 \mathrm{O}$ composite as an excellent photo-Fenton catalyst under neutral condition. J. Colloid Interface Sci., 2016, 475, 119125

[73] Zhai Q., Zhang L., Zhao X., Chen H., Yin D., Li J. A novel ironcontaining polyoxometalate heterogeneous photocatalyst for efficient 4-chlorophennol degradation by $\mathrm{H} 2 \mathrm{O} 2$ at neutral $\mathrm{pH}$. Appl. Surf. Sci., 2016, 377, 17-22

[74] Zhang R., You H., Wu D. Advanced treatment of coking wastewater by heterogeneous photo-Fenton technology with $\mathrm{Cu} / \mathrm{Fe}$ oxide catalysts. Desalin. Water Treat., 2016, 57 (26), 12010-12018.

[75] Qin L., Zhang G., Fan Z., Wu Y., Guo X., Liu M. Templated fabrication of hierarchically porous Fe-Ti bimetallic solid superacid for efficient photochemical oxidation of azo dyes under visible light. Chem. Eng. J., 2014, 244, 296-306.

[76] Tian S., Zhang J., Chen J., Kong L., Lu J., Ding F., Xiong Y $\mathrm{Fe}_{2}\left(\mathrm{MoO}_{4}\right)_{3}$ as an effective photo-fenton-like catalyst for the degradation of anionic and cationic dyes in a wide $\mathrm{pH}$ range. Ind. Eng. Chem. Res., 2013, 52 (37), 13333-13341.

[77] Mazille F., Schoettl T., Klamerth N., Malato S., Pulgarin C. Field solar degradation of pesticides and emerging water contaminants mediated by polymer films containing titanium and iron oxide with synergistic heterogeneous photocatalytic activity at neutral $\mathrm{pH}$ Water Res., 2010, 44 (10), 3029-3038

[78] Mendez-Arriaga F., Almanza R.Water remediation by UV-vis $/ \mathrm{H}_{2} \mathrm{O}_{2}$ process, photo-Fenton-like oxidation, and zeolite ZSM5. Desalin. Water Treat., 2014, 52 (31-33), 5822-5832.

[79] Gonzalez-Olmos R., Martin M.J., Georgi A., Kopinke F.-D., Oller I., Malato S.Fe-zeolites as heterogeneous catalysts in solar Fentonlike reactions at neutral pH. Appl. Catal. B-Environ., 2012, 125, 5158

[80] Zhang J., Hu F.-T., Liu Q.-Q., Zhao X., Liu S.-Q.Application of heterogenous catalyst of tris $(1,10)$-phenanthroline iron(II) loaded on zeolite for the photo-Fenton degradation of methylene blue. React. Kinet., Mech. Cat., 2011, 103 (2), 299-310.

[81] Huang Z., Wu P., Gong B., Yang S., Li H., Zhu Z., Cui L. Preservation of glutamic acid-iron chelate into montmorillonite to efficiently degrade Reactive Blue 19 in a Fenton system under sunlight irradiation at neutral Ph. Appl. Surf. Sci., 2016, 370, 209217.

[82] Barreca S., Colmenares J.J.V., Pace A., Orecchio S., Pulgarin C. Neutral solar photo-Fenton degradation of 4-nitrophenol on ironenriched hybrid montmorillonite-alginate beads (Fe-MABs). $J$. Photochem. Photobiol A, 2014, 282, 33-40.

[83] de Mendonca F.G., Rosmaninho M.G., da Fonseca P.X., Soares R.R., Ardisson J.D., Tristao J.C., Lago R.M. Use of iron and bio-oil wastes to produce highly dispersed $\mathrm{Fe} / \mathrm{C}$ composites for the photo-Fenton reaction. Environ. Sci. Pollut. Res., 2016,1-6. Article in Press.

[84] Qin L., Li Z., Xu Z., Guo X., Zhang G. Organic-acid-directed assembly of iron-carbon oxides nanoparticles on coordinatively unsaturated metal sites of MIL-101 for green photochemical oxidation. Appl. Catal. B-Environ., 2015, 179, 500-508

[85] Ye X., Cui Y., Wang X. Ferrocene-modified carbon nitride for direct oxidation of benzene to phenol with visible light. ChemSusChem, 2014, 7 (3), 738-742.

[86] Yao Y., Cai Y., Lu F., Qin J., Wei F., Xu C., Wang S. Magnetic $\mathrm{ZnFe}_{2} \mathrm{O}_{4}-\mathrm{C}_{3} \mathrm{~N}_{4}$ hybrid for photocatalytic degradation of aqueous organic pollutants by visible light. Ind. Eng. Chem. Res, 2014, 53 (44), 17294-17302.

[87] Sabhi, S.; Kiwi, J. Degradation of 2,4-dichlorophenol by immobilized iron catalysts. Water Res. 2001, 35, 1994-2002

[88] Fernandez , J.; Bandara ,J.; Lopez ,A.; Buffat , P.; Kiwi, J. Photoassisted Fenton degradation of nonbiodegradable azo dye (Orange II) in Fe-free solutions mediated by cation transfer membranes. Langmuir, 1999, 15, 185-192

[89] Han Z., Guo J., Li W. Fe(bpy $)_{3}{ }^{2+}$ supported on amidoximated PAN fiber as effective catalyst for the photodegradation of organic dye under visible light irradiation. Chem. Eng. J., 2013, 228, 36-44.

[90] Liu, T.; You, H.; Chen, Q. Heterogeneous photo-Fenton degradation of polyacrylamide in aqueous solution over $\mathrm{Fe}(\mathrm{III})-\mathrm{SiO}_{2}$ catalyst. $J$. Hazard. Mater. 2008, 162, 860-865.

[91] Waite, D.T.; Morel, F.M. Photoreductive dissolution of colloida iron oxides in nature waters, Environ. Sci. Technol. 1984, 18, 860868.

[92] Demarchis, L.; Minella, M..; Nisticò, R..; Maurino, V.; Minero, C.; Vione, D. Photo-Fenton reaction in the presence of 
morphologically controlled hematite as iron source. J. Photochem. Photobiol. A: Chem. 2015, 307-308, 99-107.

[93] Lee H., Lee H.-J., Kim H.-E., Kweon J., Lee B.-D., Lee C. Oxidant production from corrosion of nano- and microparticulate zero-valent iron in the presence of oxygen: A comparative study. J. Hazard. Mater., 2014, 265, 201-207.

[94] Xu L., Wang J. Degradation of 4-chloro-3,5-dimethylphenol by a heterogeneous fenton-like reaction using nanoscale zero-valent iron catalysts. Environ. Eng. Sci., 2013, 30 (6), 294-301.

[95] Shin J., Lee Y.-C., Ahn Y., Yang J.-W. 1,4-Dioxane degradation by oxidation and sonication in the presence of different-sized ZVI in open-air system. Desalin. Water Treat., 2012, 50 (1-3), 102-114.

[96] Katsoyiannis I.A., Voegelin A., Zouboulis A.I., Hug S.J. Enhanced As(III) oxidation and removal by combined use of zero valent iron and hydrogen peroxide in aerated waters at neutral $\mathrm{pH}$ values. $J$. Hazard. Mater., 2015, 297, 1-7.
[97] Santos-Juanes L., Garcia Einschlag F.S., Amat A.M., Arques A. Combining ZVI reduction with photo-Fenton process for the removal of persistent pollutants. Chem. Eng. J., 2016. Article in Press

[98] Liu J., Ou C., Han W., Faheem, Shen J., Bi H., Sun X., Li J., Wang L. Selective removal of nitroaromatic compounds from wastewater in an integrated zero valent iron (ZVI) reduction and $\mathrm{ZVI} / \mathrm{H}_{2} \mathrm{O}_{2}$ oxidation process. $R S C A d v$., 2015, 5 (71), 57444-57452.

[99] Arzate-Salgado S.-Y., Morales-Perez A.-A., Solis-Lopez M., Ramirez-Zamora R.-M. Evaluation of metallurgical slag as a Fenton-type photocatalyst for the degradation of an emerging pollutant: Diclofenac. Catal. Today, 2015. Article in Press.

[100] Huanosta-Gutiérrez, T;. Dantas, R.F.; Ramírez-Zamora, R.M.; Esplugas, S. Evaluation of copper slag to catalyze advanced oxidation processes for the removal of phenol in water. Journal of Hazardous Materials 213-214 (2012) 325-330 